\title{
The Poomsae in Taekwondo is an effective therapy for executive function in children with Attention Deficit Hyperactivity Disorder
}

\author{
Abdelmottaleb Kadri ${ }^{*}$ \\ Higher Institute of Sport and Physical Education of Ksar Said, University of Manouba, Manouba 2010, Tunisia
}

*Corresponding author: Abdelmottaleb Kadri, Higher Institute of Sport and Physical Education of Ksar Said, University of Manouba, Manouba 2010, Tunisia, Tel : 98442970, E-mail : abdelmottalebkadri@gmail.com

Citation: Abdelmottaleb Kadri (2021) The Poomsae in Taekwondo is an effective therapy for executive function in children with Attention Deficit Hyperactivity Disorder. SAJ Case Report 8: 104. doi: 10.18875/2375-7043.8.104

\begin{abstract}
Attention Deficit Hyperactivity Disorder (ADHD) is pathology of genetic and neurological etiology and results in significant impairment of social and academic activity among children. Martial arts play an important role in the development of cognition especially among children with ADHD. The cognitive complexity of physical activity in Taekwondo Training Program is exemplified in poomsae ("forms"), which is a series of choreographic physical movements performed with technical precision in a particular order. Executive functions are the neuropsychological processes that underlie selfregulation. They allow the person to coordinate all of his behavior in a flexible and precise manner, according to the everchanging demands of his environment as well as of his personal state. They are highly dependent on inhibition processes for their proper functioning. In this context the objective of this research was to investigate the impact of Taekwondo Training on executive function in children with Attention Deficit Hyperactivity Disorder (ADHD). First, paired and independent sample t-Tests were performed to compare the attention and executive function of the two groups before and after the Taekwondo Training Program. Subsequently, independent sample t-tests were performed to compare the performance of the Taekwondo group (TKD) and the control group at Time 1 (T1) and Time 2 (T2). The results presented indicate that the Poomsae Movement and Technique Training Program resulted in a significant difference in performance in working memory tasks (MTN1 and MTN2) (WAIS-IV) $(\mathrm{M}=0.58)(\mathrm{M}=3.41)$. $)(\eta 2=0.41)$ after the procedure. Also, the total executive flexibility task score N1 (Stroop) was significantly higher in the TKD group $(\mathrm{M}=1.99)$ than in the control group $(\mathrm{M}=4.32)(\eta 2=0.20)$. In addition, the total score for the other cognitive flexibility task N2 (Stroop) was significant in the TKD group $(M=6.40)$ compared to the control group $(M=11.21)(\eta 2=0.19)$. The results presented indicate that the Poomsae Movement and Technique Training Program also resulted in a significant difference in the performance of selective visual attention and mental flexibility tasks between the TKD group and control groups in T2. At the level of selective visual attention, the number of errors is significantly lower in the experimental group $(\mathrm{M}=2.58)$ than in those who $\operatorname{did} \operatorname{not}(M=5.69)$. With respect to executive functions, the number of errors in the task of mental flexibility is significantly lower in the TKD group that received the Training Program $(M=1.86)$ than in the control group $(M=2), 93)(\eta 2=0.40)$. In summary, a significant improvement in the rates of errors in selective visual attention tasks and cognitive flexibility is observed between T1 and T2 in the TKD group. In conclusion, the Poomsae Movement and Technique Training Program can help children with ADHD improve their cognitive function. Teens with ADHD also showed a high rate of adherence (100\%) to Taekwondo Training. Our results suggest that Taekwondo Training Program can be a fun, feasible and effective therapeutic option for children with ADHD.
\end{abstract}

Keywords: ADHD Disorder; Executive Functions; Taekwondo; Martial Art 


\section{Introduction}

According to the Diagnostic and Statistical Manual of Mental Disorders, 5th version [1], ADHD can be expressed in three ways: with hyperactivity and impulsivity only, with inattention only, or by combining these two types of expression. [2]. the work published so far tends towards a dual source of ADHD, one of genetic origin and the other of environmental order [3]. According to this Barkley model, executive function deficit would explain much of the typical heterogeneous symptomatology of ADHD, leading to a lack of behavioral control and difficulty in maintaining attention.

Recent literature reviews suggest that physical exercise can help the development of cognition, memory, selective attention and motor reaction time [4], especially in children with ADHD [5]. In this context, the Taekwondo Training deserves further investigation into their effects on executive function. Taekwondo is a Korean martial art refined over generations that engages students in a cognitive, physical, emotional, social and educational process [6]. Integration into Taekwondo is a mature behavioral philosophy that emphasizes self-control, respect, integrity, perseverance, goal setting and concentration [7]. At the heart of Taekwondo, there is an exercise-based approach to complex physical activity that involves planning, problem-solving and changing positions [8]. The cognitive complexity of physical activity in Taekwondo Training is illustrated in Poomsae "forms" "Poom" means "form, movement" and "Sae", "identity, style". Poomsae, in addition to being technical references that are a series of choreographic physical movements performed with technical precision in a particular order, [9]. The Poomsae contains technical principles and movements, is a working core of the executive functions par excellence in these children with ADHD. It is the Taekwondo Program Training «in which our basic study is based. Taekwondo received more empirical attention and benefits for children with ADHD, Cognitive and behavioral Taekwondo received more empirical attention and benefits for children with ADHD, Cognitive and behavioral that's why Children receiving Taekwondo Training showed greater gains than children in standard physical education on all dimensions of executive functions studied [10]. Children with ADHD following the Taekwondo Program Training showed greater gains than the control group on all the dimensions of the executive functions studied. ADHD is the most common behavioral disorder among young people [11]. Many causal factors have been implicated in the development and treatment of ADHD, including neurological, hereditary, pre- and post-natal care and various toxic influenced [12]. The most recent explanations of ADHD have focused on the central impaired behavioral inhibitions of the disorder [13]. Young people with ADHD are also considered at risk of rejection due to poor development of basic motor skills, poor coordination, and low levels of attentional and executive skill, in specific areas of capacity [14]. It appears that interventions for ADHD are often combined and maintained for long periods of time to support the initial effects of treatment (Barkley, 2006). The interventions of this martial art, the interpersonal relationships, the resulting intrapersonal actions, the reactions and the movements that occur have been observed. These conditions can help executive functioning, peer acceptance and personal well-being among children with ADHD [15]. It is from a program of intervention "the Poomsae Movement and Technique Training Program" that the executive functions of children with ADHD were explored in this research. The main objective of this study was to evaluate the effectiveness of the Taekwondo "Movement and Technique of Poomsae" training program on the executive function in children with ADHD. Research and theoretical information focused on improving the executive function and modifying unwanted behavior in children with ADHD through various interventions. It is from the physical activity domains in martial art that the executive functions of young people with ADHD were developed in this research study The Taekwondo Training Program influence the development and improvement of the executive functions and mastery of skill training in children with ADHD.

\section{Experimental Section}

\section{Population Selection: Inclusion/Exclusion Criteria}

The present study is a randomized controlled study registered within the Clinical Trials registry (NCT04352841). Fifty young Tunisian patients with ADHD (40 males and ten females) were recruited. They were a representative sub-sample of ADHD patients from the Tunis and Sidi Bouzid mental centers (Tunisia). TKD group $(n=25$, age $=9.1 \pm 3.27$ years, 20 males and five females) or a control group ( $n=25$, age $=9.5 \pm 3.57$ years, 20 males and five females). A total sample size of 53-61 members was required. As such, a total sample size of 50 individuals was chosen, who attended all practice sessions. Of note, concerning the TKD group, the participants were of a white belt level pre- Training Program. They achieved a blue belt level post-intervention. 
To be eligible to participate in the study, participants were required to meet the following criteria: (1) No history of chronic disease, bronchospasm or atopy; (2) Regular eating patterns; (3) No respiratory infection during the previous month. (4) Abstinence from strenuous exercise in the $48 \mathrm{~h}$ before testing (5). Not being color blind or vision-impaired.

initial information about the diagnosis was provided by the parents or teachers and their records in the center, the diagnosis of these participants was made by domain specialists in the center. Before data collection, consent of the parents, the child's consent form and the medical discharge form were obtained from each participant. The protocols for this study were approved by a committee institutional review in accordance with the 1964 Helsinki declaration and its subsequent amendments.

The study was conducted from June 2017 to December 2018. The participants were familiarized with the testing procedures at visit 1 the first visit was assigned before one week of the Taekwondo Training and consisted of the collection of anthropometric data. Furthermore, participants were familiarized with the All tests were performed in the center Ruff' 2 and 7 [16]. The Stroop test for the assessment of sustained and selective visual attention [17] as well as with Number of Digits (WAIS-IV) [18]. During the second visit, participants were asked to perform the above mentioned tests, A rest interval of at least 5-min was provided between tests. The same tests were also performed after each condition during the third visit, 1 day after the last training session. The participants of the TKD group performed various specific TKD techniques and poomsaes. The participants of the control group engaged in physical activities, including athletics, handball and football, during three sessions of physical education per week at school. Participants were advised to avoid cognitive exercise, and caffeine consumption, $48 \mathrm{~h}$ before each laboratory visit. Food and fluid intake was registered $48 \mathrm{~h}$ prior to the first study visit, and subjects were asked to avoid such intake $3 \mathrm{~h}$ before the second visit

\section{Measures}

\section{Number of Digits (WAIS-IV)}

Series of numbers, starting with three consecutive numbers and a maximum of eight consecutive numbers, are read to the participant. In the first subtask (ahead), the participant is prompted to repeat the series of numbers. In the second (backward) subtask, the participant is prompted to repeat the numbers, but in the reverse order. This test evaluates short memory and working memory, respectively. In the first subtask, the participant is prompted to repeat the series of numbers. In the second subtask, the participant is asked to repeat the numbers, but in reverse order.

\section{Stroop trial (4 colors)}

The Stroop test is composed of four conditions. For the first condition (reading), the subject must read words (of colors) as quickly as possible on a sheet. For the second condition (color denomination), the subject must name the color of the rectangles on the sheet as quickly as possible. For the third condition (interference), the subject must say, as quickly as possible, the color of the ink with which the words are written. For the last condition (flexibility), it is to say as quickly as possible the color of the ink with which the words are written. However, when a word is framed, you must read the word and not say the color of the ink.

\section{Ruff 2 and 7}

To evaluate it, we used Baillargeon's French adaptation of Ruff' 2 and 7. Ruff's selective attention test consists of a series of 20 blocks of three lines and the subject must strike out, with a pencil, the numbers 2 and 7 which are scattered among several destroyers. After this time, the subject is asked to move to the next block and so on. The search for targets is done under two conditions. In the first, the targets are distributed among destroyers belonging to a different category. This condition relies on a detection using an automatic process of attention. In the second condition, the targets are hidden among destroyers belonging to the same category. 


\section{Poomsae Movement Taekwondo Training Program “PMTTP”}

Participants in the TKD Training Program performed 50 min of various martial arts techniques three times per week for a year and a half. The program training took place in private martial arts Dojang (researcher). The TKD Program Training consisted of 10 minutes of warm-up, 10 minutes of blocking, punching and kicking, 20 minutes of Poomsae based on Taegeuk (blocking, hitting, turning hitting, out ward strike, Front kick, Side kick, Step (forward, side, backward) and 10 minutes of recovery. Taekwondo Training is exemplified in Poomsae "Forms", which is a series of choreographic physical movements performed with technical precision in a particular order that involves planning, problem solving and changing position. The practitioner also exerts inhibitory control by focusing attention on his executive actions. the main purpose of the poomsae was to impart techniques and philosophical significance and to refine the mind, human nature and emotions. Thus each poomsae conveys a value or a state of mind. The (Il jang) is symbolized by the sky, sign of the beginner, the (Yi jang) is symbolized by the lake, which learns calm, the (Sam jang) is symbolized by fire, which learns friendship, the (Sa jang) is symbolized by thunder, which teaches courage, etc. The poomsae is therefore also a work of character improvement aimed at highlighting executive qualities. An example of the TKD Training Program diagram was provided and conducted by qualified TKD instructors, including the principal investigator.

\begin{tabular}{|c|c|c|c|c|}
\hline Program & $\begin{array}{l}\text { Static } \\
\text { activity }\end{array}$ & Dynamic activity & $\begin{array}{l}\text { executive functions } \\
\text { targeted }\end{array}$ & Time min) \\
\hline Echauffement & \multicolumn{2}{|c|}{$\begin{array}{l}\text { Stretching, jogging and strengthening (sit-up and } \\
\text { push-up) }\end{array}$} & & Ten \\
\hline Blocks and body punch & $\begin{array}{l}\text { Defense } \\
\text { position }\end{array}$ & Walk forwards / backwards & \multirow{6}{*}{$\begin{array}{l}\text { Selective visuel } \\
\text { attention }\end{array}$} & Five \\
\hline \multicolumn{3}{|l|}{ Upper } & & \multirow{5}{*}{ Five } \\
\hline Down & $\begin{array}{l}\text { Large } \\
\text { position }\end{array}$ & Wolking back ward / forward & & \\
\hline Inside & & & & \\
\hline \multirow{2}{*}{$\begin{array}{l}\text { Out side } \\
\text { Kicking }\end{array}$} & & & & \\
\hline & & & & \\
\hline $\begin{array}{l}\text { Front } \\
\text { Lateral } \\
\text { On the back }\end{array}$ & $\begin{array}{l}\text { Fighting } \\
\text { position }\end{array}$ & Walking forward / backward & \multirow{3}{*}{$\begin{array}{l}\text { Visual Sustained } \\
\text { Attention }\end{array}$} & \\
\hline Tour yourself & & Jump & & \\
\hline \multicolumn{4}{|l|}{ Side } & \\
\hline $\begin{array}{l}\text { Poomsae } \\
\text { Kids Taekwondo } \\
\text { Poomsae Training }\end{array}$ & $\begin{array}{l}\text { Taegeuk } \\
(1-5)\end{array}$ & $\begin{array}{l}\text { Forward / backward } \\
\text { Left right } \\
\text { Turn in yourself } \\
\text { Down To the top } \\
\text { No foot wide / short } \\
\text { (blocking, hitting, turning hitting, out } \\
\text { ward strike, Front kick, Side kick, } \\
\text { Step (forward, side, backward) }\end{array}$ & $\begin{array}{l}\text { Balanced } \\
\text { Agility } \\
\text { Vigilance } \\
\text { Confirmation }\end{array}$ & $\begin{array}{l}\text { Alternation / } \\
\text { attentional } \\
\text { Flexibility }\end{array}$ \\
\hline
\end{tabular}




\begin{tabular}{|l|l|l|l|l|l|}
\hline Technical & $\begin{array}{l}\text { Looking forward } \\
\text { Efficiency }\end{array}$ & $\begin{array}{l}\text { Coordination } \\
\text { Attentait } \\
\text { Target }\end{array}$ & $\begin{array}{l}\text { Learning } \\
\text { Auditory work } \\
\text { memory } \\
\text { Verbal working } \\
\text { memory } \\
\text { Visual work memory }\end{array}$ & Twenty \\
\hline & & & & & \\
\hline & Placement & Softness Flexible & Self-regulation & \\
\hline Relaxation & & Stretching group game & Concentration calm & Ten \\
\hline
\end{tabular}

The Poomsae Movement and Technique Training Program "PMTTP”

\section{Statistical Analysis}

Statistical analyzes were performed using SPSS version 21.0 for Windows (SPSS Inc., Chicago, IL, USA). Data were presented as the mean \pm standard deviation, unless otherwise indicated. To identify differences in the normally distributed results, the two-way repeated ANOVA analysis was used. When significant group-by-time interactions occurred, single major effects were assessed using independent and paired t-tests. The level of significance was set at (p0.05) for all tests. Average comparison analyzes were performed on the variables under study due to the presence of only two groups and one independent variable (the type of intervention). As a first step, paired sample t-tests were performed to compare the cognitive and behavioral function of the TKD group before and after the Poomsae Movement and Technique Training Program. Subsequently, independent sample t-tests were performed to compare the performance of the TKD group and the control group at Time 1 (T1) and Time 2 (T2). Thus, unilateral t-tests and bilateral t-tests were favored.

\section{Results}

The Taekwondo Training on executive function tests in the experimental and control groups

The results shown in Table (1) show that the Poomsae Movement and Technique Training Program resulted in a difference in

\begin{tabular}{|c|c|c|c|c|c|c|c|c|c|c|c|c|}
\hline \multicolumn{7}{|c|}{ TKD GROUP } & \multicolumn{6}{|c|}{ CONTROL GROUP } \\
\hline variables & & $\mathbf{T}$ & ddl & $\begin{array}{l}\text { unilat } \\
\text { eral Sig }\end{array}$ & $\begin{array}{l}\text { Aver } \\
\text { age T1 }\end{array}$ & Average T2 & & $\mathbf{T}$ & ddl & $\begin{array}{l}\text { unilate } \\
\text { ral Sig }\end{array}$ & Average T1 & Average T2 \\
\hline \multirow{2}{*}{$\begin{array}{l}\text { selective } \\
\text { visual } \\
\text { attention }\end{array}$} & TE & $-0,51$ & 9 & 0,38 & $1,43(0,63)$ & $1,30(1,06)$ & TE & $-0,62$ & 9 & 0,47 & $1,27(1,02)$ & $1,51(0,96)$ \\
\hline & TR & $-0,51$ & 9 & 0,38 & $1,43(0,63)$ & $1,30(1,06)$ & TR & 2,46 & 9 & $0,10^{*}$ & $239,41(41,32)$ & $260,21(25,74)$ \\
\hline \multirow{2}{*}{$\begin{array}{l}\text { Visual } \\
\text { Sustained } \\
\text { Attention }\end{array}$} & TE & 1,93 & 9 & 0,09 & $6,23(6,31)$ & $3,51(2,93)$ & TE & 2,46 & 9 & $0,10^{\star}$ & $239,41(41,32)$ & $260,21(25,74)$ \\
\hline & TR & 0,88 & 9 & 0,24 & $448,14(32,51)$ & $439,20(32,43)$ & TR & 2,46 & 9 & $0,10^{*}$ & $239,41(41,32)$ & $260,21(25,74)$ \\
\hline \multirow{2}{*}{$\begin{array}{l}\text { Visual } \\
\text { attentional } \\
\text { alternation }\end{array}$} & TE & 3,41 & 9 & $0,006^{\star *}$ & $2,98(2,29)$ & $0,77(1,11)$ & TE & 2,46 & 9 & $0,10^{*}$ & $239,41(41,32)$ & $260,21(25,74)$ \\
\hline & TR & 5,67 & 9 & $0,003^{* *}$ & $64,12(12,31)$ & $52,49(7,62)$ & TR & 5,83 & 9 & $0,005^{\star *}$ & $61,33(10,01)$ & $73,17(12,41)$ \\
\hline
\end{tabular}

${ }^{*} \mathrm{p} \geq 0.05 ;{ }^{* *} \mathrm{p} \geq 0.01$

Note. The Standard deviation is in parentheses. TE = error rate; $\mathrm{TR}=$ average response times; $\mathrm{ddl}=$ degrees of freedom;

Table 1: The TKD and the control group for paired samples on the error rates and the response times of the attention variables of the two groups before and after the Taekwondo Training

performance among participants who received the program, in terms of selective visual attention and sustained attention. It is the same with regard to selective attention and attentional alternation in auditory visual modality. In visual modality, we find for the TKD group, a significant difference in mean error rates and response times between $\mathrm{T} 1$ and $\mathrm{T} 2$ for the variables of selective visual attention, sustained attention and alternation of attention. On the one hand, the average response time for the visual selective attention task is significantly lower after $(\mathrm{TR}=248.41)$ than before the Poomsae Movement and Technique Training Program (TR $=259.21)$. On the other hand, the number of errors in the task of sustained visual attention is significantly lower after $(\mathrm{TR}=3.51)$ 
than before the Poomsae Movement and Technique Training Program $(T R=6.23)$ and the size of this effect is large $(\eta 2=0.54)$. In addition, the number of errors in the task of visual alternation is significantly lower in T2 (TE $=0.77)$ than in T1 (TE $=2.98)$, the size of this effect being considered large $(\eta 2=0.55)$. The average response time for this same task is, for its part, significantly lower after $(\mathrm{TR}=52.49)$ than before the Poomsae Movement and Technique Training Program $(\mathrm{TR}=64.12)$, in the presence again, of a large effect $(\eta 2=0.73)$. In visual modality, a significant difference is observed in error rate averages for the variables of visual selective attention, visual attention and visual attention alternation.

\begin{tabular}{|c|c|c|c|c|c|c|c|c|c|c|c|c|}
\hline \multicolumn{7}{|c|}{ TKD GROUP } & \multicolumn{6}{|c|}{ CONTROL GROUP } \\
\hline variables & & $\mathrm{T}$ & ddl & $\begin{array}{l}\text { unilat } \\
\text { eral Sig }\end{array}$ & Average T1 & Average T2 & & $\mathrm{T}$ & ddl & \begin{tabular}{|l|} 
unila \\
teral Sig
\end{tabular} & Average T1 & Average T2 \\
\hline \multirow{2}{*}{$\begin{array}{l}\text { Working } \\
\text { memory N1 }\end{array}$} & TE & 2,07 & 9 & 0,08 & $2,34(2,15)$ & $0,58(0,91)$ & TE & 3,01 & 9 & 0,37 & $2,26(2,01)$ & $3,41(1,72)$ \\
\hline & TR & $-0,49$ & 9 & 0,55 & $655,21(173,64)$ & $647,32(170,17)$ & TR & $-0,68$ & 9 & 0,64 & $643,40(168,33)$ & $693,21(172,40)$ \\
\hline \multirow{2}{*}{$\begin{array}{l}\text { Working } \\
\text { memory N2 } \\
\text { (auditory-verbal } \\
\text { and visual }\end{array}$} & TE & TE 0,22 & 9 & 0,50 & $6,51(4,22)$ & $4,35(4,32)$ & TE & 0,44 & 9 & 0,92 & $5,79(3,52)$ & $7,65(2,93)$ \\
\hline & TR & 1,92 & 9 & 0,10 & $797,31(155,63)$ & $707,14(153,81)$ & TR & 1,37 & 9 & 0,85 & $780,22(134,72)$ & $797,26(123,34)$ \\
\hline \multirow{2}{*}{$\begin{array}{l}\text { Cognitive } \\
\text { flexibilityN1 }\end{array}$} & TE & 1,86 & 9 & 0,04 & $3,07(1,43)$ & $1,99(1,12)$ & TE & 1,97 & 9 & 0,09 & $2,76(1,12)$ & $4,32(1,83)$ \\
\hline & TR & $-1,65$ & 9 & 0,09 & $471,20(57,12)$ & $511,00(112,01)$ & TR & $-1,60$ & 9 & 0,14 & $450,33(66,17)$ & $574,00(126,20)$ \\
\hline \multirow{2}{*}{$\begin{array}{l}\text { Cognitive } \\
\text { flexibilityN2 }\end{array}$} & TE & 1,94 & 9 & $0,04^{*}$ & $10,15(5,83)$ & $6,40(2,68)$ & TE & 1,89 & 9 & $0,03^{*}$ & $9,63(4,54)$ & $11,21(2,11)$ \\
\hline & TR & 1,93 & 9 & $0,04^{*}$ & $812,14(261,45)$ & $701,19(131,97)$ & TR & 1,91 & 9 & $0,05^{*}$ & $800,26(242,81)$ & $873,20(144,23)$ \\
\hline
\end{tabular}

${ }^{*} \mathrm{p} \geq 0.05 ;{ }^{* *} \mathrm{p} \geq 0.01$

Note. The Standard deviation is in parentheses. TE = error rate; TR = average response Times; $\mathrm{ddl}=$ degrees of freedom

Table 2: The TKD and Control Groups for paired samples on error rates and response times of the executive variables before and after the Taekwondo Training

The results of the t-tests are shown in Table 2 and indicate that the Poomsae Movement and Technique training program has resulted in improved performance in MCT and MT, memory and visual learning and mental flexibility among participants in the experimental group. Indeed, the number of errors is significantly lower between the T2 $(\mathrm{M}=0.58)$ and the $\mathrm{T} 1(\mathrm{M}=2.34)$ at the task of MT1 and MT2. In addition, a significant difference in mean is observed between T1 and T2 for the visual learning and visual memory variables. In fact, the results of learning on the working memory task 2 are significantly lower after $(\mathrm{M}=4.35)$ than before the intervention $(\mathrm{M}=6.51)$. In addition, the average of the total score for this task is significantly higher in $\mathrm{Q} 2$ than in $\mathrm{T} 1$ for the experimental group. With respect to executive measures, the total score on cognitive flexibility N1 was more significant after the intervention $(M=3.07)$ than before the intervention $(M=1.99)$. Similarly, the total score for the other cognitive flexibility task N2 (WAISIV) was greater after the Training Program $(M=6.40)$ than before $(M=10.15)$ and the height its effect is also considered large $(\eta 2=0.25)$.

The results presented in the Tables indicate that the Poomsae Movement and Technique Training Program resulted in an improvement in selective visual and auditory attention as well as mental flexibility. The response time averages at the word reading task are significant TKD group and time 2 control $(M=24.16)(M=27.33)$ and the size of this difference is large $(\eta 2=0.41)$. This difference represents a large effect $(\eta 2=0.49)$. The number of errors is significantly lower after $(M=4.31)(M=7.58)$ and the size associated with this effect is large. $(\eta 2=0.91)$. In with respect to executive functions, the mental flexibility task error rates are lower for the experimental group $(\mathrm{M}=1.86)(\mathrm{M}=4.74)$ after the Poomsae Movement and Technique Training Program. In addition, at the same task, mean response times are also lower for the experimental group in $\mathrm{T} 2(\mathrm{M}=52.60)(\mathrm{M}=67.19)$.

Thus, it is necessary that the averages of the TKD group be different from the means of the T1 control group, so that the changes in T2 can be attributed to an initial divergence between the two groups. In visual mode, the number of errors in the attention task was significantly lower in the experimental group $(\mathrm{M}=3.51)$ compared to the control group $(\mathrm{M}=7.68)$. The complementary analysis using the eta-square suggests that the size associated with this effect is large $(\eta 2=0.46)$. Also, the number of attentional alternation task errors was significantly lower in the experimental group $(\mathrm{M}=0.77)$ than in the control group $(\mathrm{M}=1.89)$. The 
response times for this task are also significantly lower for the experimental group $(\mathrm{M}=52.49)$ than for the control group $(\mathrm{M}=$ 73.17) after the intervention. In summary, a significant improvement in the error rates and response times of the visual alternation task was observed between T1 and T2 in the experimental group. Thus, the "Poomsae Movement and Technique" attentional processes training program resulted in a significant improvement in visual attention alternation among young people with ADHD.

\begin{tabular}{|c|c|c|c|c|c|c|c|c|c|c|c|c|}
\hline \multicolumn{7}{|c|}{ TKD GROUP } & \multicolumn{6}{|c|}{ CONTROL GROUP } \\
\hline variables & & $\mathrm{T}$ & ddl & \begin{tabular}{|l|} 
unila \\
teral Sig
\end{tabular} & Average T1 & Average T2 & & $\mathbf{T}$ & ddl & \begin{tabular}{|l|} 
unilat \\
eral Sig
\end{tabular} & $\begin{array}{l}\text { Aver } \\
\text { age T1 }\end{array}$ & Average T2 \\
\hline \multirow{2}{*}{$\begin{array}{l}\text { selective } \\
\text { visual } \\
\text { attention }\end{array}$} & TE & 1,53 & 9 & 0,21 & $6,33(6,29)$ & $2,58(2,61)$ & TE & 1,65 & 9 & 0,28 & $6,01(6,35)$ & $7,58(4,67)$ \\
\hline & TR & 2,75 & 9 & & $237,55(27,83)$ & $219,45(21,10)$ & TR & 2,89 & 9 & $0,02^{\star *}$ & $229,61(24,41)$ & $238,50(27,91)$ \\
\hline \multirow{2}{*}{$\begin{array}{l}\text { Attention } \\
\text { Control / } \\
\text { Inhibition }\end{array}$} & TE & 1,49 & 9 & 0,14 & $2,79(1,86)$ & $1,02(1,38)$ & TE & 1,55 & 9 & 0,19 & $2,60(1,93)$ & $3,02(2,23)$ \\
\hline & TR & $-0,05$ & 9 & 0,51 & $566,17(57,91)$ & $551,23(79,44)$ & TR & $-0,07$ & 9 & 0,56 & $529,19(65,33)$ & $589,31(83,21)$ \\
\hline \multirow{2}{*}{$\begin{array}{l}\text { direct } \\
\text { Empan } \\
\text { Indirect } \\
\text { Empan }\end{array}$} & ST & $-1,12$ & 9 & 0,17 & & $6,61(1,88)$ & TE & $-1,14$ & 9 & 0,18 & & $7,42(2,19)$ \\
\hline & ST & $-0,66$ & 9 & 0,40 & $5,16(1,67)$ & $5,41(1,08)$ & TR & $-0,76$ & 9 & 0,29 & $4,79(1,33)$ & $6,58(1,43)$ \\
\hline \multirow{2}{*}{$\begin{array}{l}\text { Flexibility / } \\
\text { Alternation }\end{array}$} & TE & 2,21 & 9 & $0,05^{\star}$ & $3,35(2,89)$ & & TE & 2,11 & 9 & $0,05^{\star}$ & & $4,74(1,20)$ \\
\hline & TR & 3,09 & 9 & $0,01^{\star *}$ & $62,80(12,90)$ & $52,60(9,40)$ & TR & 3,09 & 9 & $0,01^{\star *}$ & $56,72(10,86)$ & $67,19(7,46)$ \\
\hline \multirow{2}{*}{$\begin{array}{l}\text { Reading } \\
\text { words }\end{array}$} & TE & 0,10 & 9 & 0,60 & $0,37(0,57)$ & $0,37(0,57)$ & TE & 0,40 & 9 & 0,81 & $0,29(0,37)$ & $0,92(0,77)$ \\
\hline & TR & 2,74 & 9 & $0,04^{*}$ & $26,42(2,93)$ & $24,16(5,01)$ & TR & 2,64 & 9 & $0,02^{*}$ & $24,42(2,93)$ & $27,33(4,89)$ \\
\hline
\end{tabular}

${ }^{*} \mathrm{p} \geq 0.05 ;{ }^{* *} \mathrm{p} \geq 0.01$

Note. The Standard deviation is in parentheses. TE = error rate; TR = average response times; $\mathrm{ST}=$ Total score - $\mathrm{ddl}=\mathrm{degrees}$ of freedom;

Table 3: The TKD and control group for matched samples on error rates and response times and total scores of secondary attentional and executive variables before and after the Taekwondo Training

Using the results of the independent two-tailed t-tests presented in Table 4-5, it is shown that the groups do not differ in T1 for the majority of the variables, except for the visual learning. Thus, with the exception of the visual learning variable, the averages of scores obtained for mnemonic and executive tasks can be compared to T2. The results presented in the Tables indicate that the "Movement and Technique of Poomsae" Training Program resulted in a significant difference in performance with MTN1 and MTN2 tasks and mental flexibility between TKD and control groups in T2. Indeed, the number of task errors of MTN1 and MTN2 is significantly lower in the TKD group $(\mathrm{M}=0.58)$ than in the control group $(\mathrm{M}=3.41)$ after the intervention. Also, the total score on the task of cognitive flexibility N1 (Stroop) was significantly higher in the experimental group (M = 1.99) than in the control group $(M=4.32)$ in the presence of a large patient size, effect $(\eta 2=0.20)$. In addition, the total score on the other cognitive flexibility task N2 (Stroop) was significant in the experimental group $(M=6.40)$ compared to the control group $(\mathrm{M}=11.21)$. In summary, a significant improvement in error rates and in short-term memory tasks and working memory and cognitive flexibility is observed between $\mathrm{T} 1$ and $\mathrm{T} 2$ in the experimental group. Using the results of the independent sample t-tests presented in the tables, it is now clear that the groups stand out in the T1 on the majority of the variables apart from the variable of selective attention. Indeed, the average response time is significantly lower between the experimental group $(\mathrm{M}=237.55)$ and the control group $(M=228.45)$ in $T 1$. The results presented in the Tables indicate that the Poomsae Movement and Technique Training Program also resulted in a significant difference in performance with selective attention and mental flexibility tasks between the TKD and control groups in T2. At the level of selective attention, the number of errors is significantly lower in the experimental group $(M=2.58)$ than in those who did not $(M=5.69)$. With respect to executive functions, the number of errors in the task of mental flexibility is significantly lower in the group that received the training program $(\mathrm{M}=1.86)$ than in the control group $(M=2,93)$. In summary, a significant improvement in error rates in selective attention tasks and cognitive flexibility was observed between T1 and T2 in the experimental group. Thus, the Poomsae Movement and Technique training program allows significant improvement in executive function in children people with ADHD. 


\section{Discussion}

The main objective of this study was to evaluate the effectiveness of the Taekwondo Poomsae Movement and Technique Training Program on executive function in children with ADHD.

First, to study the improvement of Poomsae Movement Taekwondo Training Program "PMTTP" on executive functions. The results of the present study indicate, for ADHD participants who received the Poomsae Movement Taekwondo Training Program "PMTTP" had significant improvements in the level of selective visual attention and attentional alternation. The visual selective attention task performance was better for the group receiving the Poomsae Movement and Technique Training Program. Following the Training Program, the significant reduction in the number of selective attention task errors (visual synchronous Ruff 2-7) was observed in the TKD group compared to the control group. Thus, as a result of the Poomsae Movement Taekwondo Training Program "PMTTP", participants are better at recognizing a stimulus among several other distractors, regardless of their saliency [19]. Similarly, in several visual tasks, the participant was timed to improve his performance not only in the number of errors, but also in terms of time. It was clearly explained to the participant that this approach was aimed at a more comprehensive improvement in attentional effectiveness. Thus, it is possible that the selective attention has developed because of the attentive vigilance solicited during the Poomsae Movement Taekwondo Training Program "PMTTP" sessions. In addition, the intensity of the Training Program (three per a week for one and a half years) may have contributed to improved performance in selective attention tasks after the Poomsae Movement Taekwondo Training Program "PMTTP" [20]. The presence of an improvement of the visual selective attention by this training program MTP thus seems, as described in the model of Van Zomeren and Brouwer [21], to have improved the state of vigilance, more specifically at the level of its phasic dimension. However, this improvement is also observed in the group having received the program and thus increases the specificity of the improvement of the visual selective attention to the training program. The present study used the Stroop color and word test to test the effect of TKD training on cognitive function in adolescents with ADHD. The result showed that the experimental group achieved significantly higher Color-Word scores after the one-and-a-half-year training, suggesting that Poomsae Movement Taekwondo Training Program "PMTTP" can be effective in improving executive function. This confirms the results of previous research that reported a significant increase in Stroop Color and Word Test scores following regular Taekwondo training [22]. As a result of the intervention, the participants who received the program made fewer mistakes and completed more quickly the mental flexibility tasks that the participants did not schedule. In the present study, some tasks typically associated with other executive functions, but which are involved when attention alternation is required, have been shown to be more successful by the TKD group compared to the control group following their respective intervention. The results show a significant improvement in visual attention control task performance in the experimental group compared to the control group after the intervention using the Poomsae Movement Taekwondo Training Program "PMTTP". This suggests that the program allowed participants to disengage and move their attention more quickly and efficiently. In the literature on this subject, it has been shown that what makes it possible to acquire better attentional control is the training of the task component comprising a deliberate and controlled attentional shift [23]. More the combination of strategies and objectives to the training tasks would allow a better generalization and improvement of this function [24]. In order to allow a progression of the training and the improvement of this component, the attentional control tasks of the Poomsae Movement Taekwondo Training Program "PMTTP" gradually became more and more complex [25]. It should be noted that there is a significant improvement in attentional control and auditory inhibition was also observed among participants who received the training. Although this improvement is marginally different from the control group, this difference is still considerably close to the significance threshold $(\mathrm{p}=0.05)$. 


\section{Conclusion}

The influence of Taekwondo martial art on cognitive function in youth with ADHD and the feelings of youth regarding their ability and success were discussed. With the participation in the Poomsae Movement Taekwondo Training Program "PMTTP" Participants' need for a realistic order and organization seemed to be nurtured participation in the program "Movement and Technique of Poomsae", appeared to be an area where children with ADHD were more engaged participants appreciated the importance of a combined approach of mental and physical abilities for maximized success. Included in this consideration were the principles of the Poomsae Movement Taekwondo Training Program “PMTTP» system formulated by the researcher (master), and their alignment with viable strategies used to work with children ADHD. More studies need to be conducted in this area in order to further explain the relationship between martial arts training and executive functions on children with ADHD but from the information collected and reviewed training time and levels of contact are key factors that must be accounted for in the relationship of these areas. 


\section{References}

1. American Psychiatric Association (2013) Diagnostic and Statistical Manual of Mental Disorders: DSM-5. 5th ed. Washington, DC: American Psychiatric Association.

2. Goulardins JB, Marques JCB, Casella EB, Nascimento RO, Oliveira JA (2013) Motor profile of children with attention deficit hyperactivity disorder, combined type. Res on Develop Disord 34: 40-5,

3. Chevalier N, Guay MC, Achim A, Lageix P, Poissant H (2006) Attention Deficit Hyperactivity Disorder: Maintain, educate, and especially value: University of Quebec Press

4. Padilla C, Mayas J, Ballesteros S, Andrés P (2017) The role of chronic physical exercise and selective attention Memory 25: 1026-35

5. Diamond A, Lee K (2011) Interventions demonstrated to support the development of executive function in children aged 4 to 12 years. Sci 333: 959-64.

6. Kim Y (2015) The effect of regular Taekwondo exercise on brain-derived neurotrophic factor and the Stroop test in an undergraduate student. J Exerc Nutrition Biochem 19: 73-9.

7. Parker HC (2001) The ABCs of ADHD: an introduction for parents and teachers. Attention 7: 32-7

8. Kyong Myong LEE (2005) Taekwondo: tradition, philosophy and culture, BUDO editions, France.

9. Jean-Pierre Fortuny Gazquez (1996) the Poomsae book, Edition Amphora, France.

10. Lakes KD, Hoyt WT (2004) Promote self-regulation through martial arts training at school. J Psychol Appl to Develop 25: 283-302.

11. Kidd PM (2000) Attention Deficit / Hyperactivity Disorder (ADHD) in Children: Rationale for Integrative Management [Electronic Version]. J Alternative Med 5: 402-38.

12. Barkley R (2006) Attention Deficit Hyperactivity Disorder. A manual for diagnosis and treatment. 3rd ed. New York: The Guilford Press.

13. Wells KC, Pelham WE, Kotkin RA, Hoza B, Abikoff HB, et al. (2000) Strategies for Psychosocial Treatment in the MTA Study: Rational, Methods and Critical Issues in Design and Implementation [Electronic Version]. J Abnormal Child Psychol 28: 483-519.

14. Lopez-Williams A, Chacko A, Wymbs BT, Fabiano GA, Seymour KE, et al. (2005) Athletic performance and social behavior as predictors of peer acceptance in children diagnosed with attention-deficit / hyperactivity disorder [Electronic version]. J Emotional and Behavioral Disord 18: 173-81

15. Colcombe SJ, K Erickson, Scalf PE, Jenny SK, Ruchika P, et al. (2006) Aerobic training increases brain volume in aging humans. J Gerontol A Biol Sci Med Sci 61: 1166-70.

16. Ruff RM, Allen CC (1996) Selective attention test Ruff 2 \& 7, professional manual. Odessa, FI: Psychological Assessment Resources

17. Chatelois J (1993) Test Stroop revised form 4 colors- "flexibility”. Unpublished document, Montreal 
18. Wechsler D (2005) Wechsler Intelligence Scale for Children and Adolescents-4th Edition (WISC IV). Paris: Editions of the Center of Applied Psychol.

19. Sohlberg MM, Mateer C (1986) Attention Process Training (APT), Puyallup: Center for Cognitive Rehabilitation.

20. Sturm W, Willmes K, Orgass B, Hartje W (1997) Do specific attention deficits require specific training? Neuropsychological rehabilitation 7: 81-103.

21. Van Zomeren AH, Brouwer WH (1994) Clinical neuropsychology of attention. New York: Oxford University Press

22. Baddeley A (2012) Work memory: theories, models and controversies. Annual Review of Psychol 63: 1-29.

23. Adams ZW, Milich R, Fillmore MT (2010) Examine the inhibition of manual and visual response among subtypes of ADHD. J Abnormal Child Psychol 38: 971-83.

24. Fuggetta GP (2006) Executive Function Deficiency in Boys with Attention Deficit / Hyperactivity Disorder Infantile Neuropsychol 12: 1-21.

25. Barkley RA (1997) Behavioral inhibition, sustained attention and executive functions: Construct a unifying theory of ADHD. Psychol Bulletin 121: 65-94. 